deliveries, with 3 post-partum haemorrhages. Birth weights ranged from $2.37 \mathrm{~kg}$ to $4.9 \mathrm{~kg}$. 155 patients had more than 2 sets of haematological investigations during pregnancy, with 83 patients having more than 5 measurements. $39.7 \%$ had haematinic investigations performed, with 48 of these patients had suboptimal ferritin levels. Only 3 patients were defined as anaemic before 12 weeks gestation.

There are currently no national guidelines regarding appropriate haematological investigations in pregnancy. This study demonstrates the demographics and frequency of haematological investigation in our population. We have also identified the proportion of anaemia demonstrated at varying gestations.

\section{PM.92 FACILITATION OF VAGINAL DELIVERY IN AN INFANT WITH COMPLETE HEART BLOCK (CHB) SECONDARY TO MATERNAL ANTI RO ANTIBODIES}

doi:10.1136/archdischild-2013-303966.173

L Tripathi, S Shebani, I Bruce, L Byrd. University hospital of central Manchester, St Mary's Hospital and MRI, Manchester, UK

A 36-year-old, G4P4 presented at 7 weeks gestation, with known Sjorgen's Syndrome (Lupus anticoagulant and Anti Ro antibody positive) and previous deep vein thrombosis. At 20 weeks gestation both anomaly and fetal echocardiogram were undertaken and confirmed as normal. However 10 days later repeat echocardiogram confirmed congenital heart block $(\mathrm{CHB})$, ventricular rate $60 \mathrm{bpm}$. There was no evidence of either fetal hydrops or heart failure. The couple was counselled regarding the potentially poor outcome.

The pregnancy continued; the fetus remained healthy albeit with CHB. Options for delivery were regularly discussed. Given both her parity and history of quick labours she was keen, if possible, to avoid surgery. Serial growth scans confirmed good growth velocity. Comprehensive evaluation of heart function and fetal circulation (CVP score) and fetal well being (Biophysical Score) was assessed and shown to be maintained throughout pregnancy and at term when she presented in early labour. Labour progressed rapidly to delivery of a female infant, in excellent condition (Apgars of 9 at 1 and 5 minutes), birth weight $3.02 \mathrm{~kg}$. The newborn was transferred to SCBU and an echocardiogram re affirmed $\mathrm{CHB}$ with good cardiac function. She established demand feeding over the next $48-72$ hours without compromise and was discharged home with mum within the week. She remains well and has not yet required pacing (age 1 year).

Discussion The strategy of close fetal surveillance using both biophysical profile (BPP) and cardiovascular profile (CVP) scoring during both pregnancy and early labour facilitated a spontaneous vaginal delivery at term.(1)

\section{REFERENCE}

1. Huhta JC. Right ventricular function in the human fetus. J Perinat Med 2001; 29:381-9.

\section{PM.93 A COMPLICATED CASE OF GIANT VULVAL CONDYLOMATA IN PREGNANCY}

doi:10.1136/archdischild-2013-303966.174

S McGowan, J McManus, S McNeil. Altnage/vin Area Hospital, Western Health and Social Care Trust, Northern Ireland, Londonderry, UK

Anogenital warts are one of the most common sexually transmitted diseases in the UK caused by HPV infection. ${ }^{12}$ The condition is not purely benign with significant symptoms present in some patients related to severity and site of disease with an increased risk of cervical and other anogenital cancers. ${ }^{2}{ }^{3} \mathrm{HPV}$ infection is higher in pregnant women with rapid growth of warts observed which is thought to be related to immunological factors. ${ }^{4}$ Treatment, even in non-pregnant individuals is difficult and cure elusive. ${ }^{5}$ Treatment options are limited in pregnancy to conservative, non-teratogenic medical management and surgery. ${ }^{45}$ We present a case of massive condylomata in a pregnant patient complicated by brittle diabetes and mental health issues.

A 30 year old parous patient presented in early pregnancy with hyperemesis, poorly controlled type1 diabetes and a massive growth of vulval warts causing severe pain and difficulty mobilising. This large exophytic mass covered the vulvae and would preclude vaginal delivery. Genito-urinary medicine suggested a conservative course of treatment. Subsequently the patient had several admissions with hyperemesis and poor glycaemic control. The patient disclosed suicidal ideation related to the vulval warts and desire to not continue pregnancy. A termination of pregnancy was requested on this basis. Psychiatry review documented a depressive episode and suicide risk. In view of these factors a surgical resection was performed. This was complicated by significant blood loss requiring return to theatre, blood transfusion and HDU admission. Currently the pregnancy is ongoing.

\section{REFERENCES}

1. Alder MW. Genital warts and molluscum contagiosum. British Medical Journal 1984;288:213-15.

2. Gall SA. Female genital warts: global trends and treatments. Infectious Diseases in Obstetrics and Gynecology 2001:9:149-54.

3. Breen D, Bleday R. Condylomata acuminata (Anogenital warts). UpToDate 2012, www.uptodate.com/contents/condylomata-acuminata-anogenital-warts (accessed October 2012).

4. Gearhart P, et al. Human Papillomavirus Treatment \& Management, Medscape, http:// emedicine.medscape.com/article/219110-overview (accessed October 2012).

5. Carusi D. Treatment of vulvar and vaginal warts, UpToDate 2012, www.uptodate.com/contents/treatment-of-vulvar-and-vaginal-warts laccessed October 2012).

\section{PM.94 THE MANAGEMENT OF A TWIN PREGNANCY IN A PATIENT WITH MAGIC SYNDROME}

doi:10.1136/archdischild-2013-303966.175

A Fabre-Gray, D Mahendran. Gloucestershire Royal NHS Foundation Trust, Gloucester, UK

In 1985 Firestein et al, first described patients with co-existent relapsing polychondritis and Behçet's Disease. They proposed the acronym MAGIC syndrome (Mouth And Genital ulcers with Inflamed Cartilage).

This is a rare condition with no more than twenty cases described in the literature to date.

This case is the first to report the management of a pregnancy in a patient with MAGIC syndrome.

The autoimmune pathogenesis can potentially damage cartilage anywhere in the body, including cardiac valves and tracheal cartilage. Therefore a multidisciplinary approach to the management of this pregnancy was paramount.

We describe her antenatal, intrapartum and post-partum management specific to this condition and demonstrate how this led to a safe delivery of her twins.

\section{PM.95 SYSTEMIC LUPUS ERYTHEMATOSUS, IMMUNOSUPPRESSION AND SOUAMOUS CELL CARCINOMA OF THE TONGUE DURING PREGNANCY}

doi:10.1136/archdischild-2013-303966.176

${ }^{1}$ JD Unsworth, ${ }^{2} \mathrm{~A}$ Baldwin, ${ }^{3} \mathrm{~L}$ Byrd. ${ }^{1}$ Fairfield General Hospital, Manchester, UK; ${ }^{2}$ North Manchester General Hospital, Manchester, UK; ${ }^{3}$ St Mary's Hospital, Manchester, UK

This case describes a 29 year old cigarette smoker with underlying Systemic Lupus Erythematosus (SLE) treated aggressively with 